\title{
Continuity of Care Model for Older Adults
}

\section{Carmen M Sarabia Cobo*}

Department of Nursing, University of Cantabria, Spain

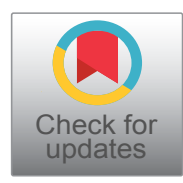

*Corresponding author: Carmen M Sarabia Cobo, PhD, RN, MSN, Department of Nursing, The House of Valdecilla Health, University of Cantabria, Avda. De Valdecilla s/n. 39008, Santander-Cantabria, Spain, Tel: 606-247-502/(+34)-942-202239, Fax: 942-20-16-93

In 2000, the world population of people over 60 was 600 million and the projection for 2050 is 2,000 million [1]. This means the consequent increase in chronic, degenerative, debilitating and, therefore, the increase in consultations and hospitalizations for this population [1]. It is important that the elderly dependent suffer numerous hospital admissions that may lead to return to his home in different conditions that he entered. It is therefore necessary to emphasize something important for nurses: the continuity of care. Sometimes there is good communication between hospital, primary care or nursing homes and if this transition between hospitalold homes is not insured incur a decline in the quality of care.

The nurse is responsible for the management of care, that is, nurse should assume the role of manager and as such care is credited with a number of functions and powers. The International Council of Nurses (ICN) [2], in relation to nursing care for the elderly, said: "Nurses, in partnership with families and with other health professionals have a key role to play in caring for older people". [2], especially if the adult is hospitalized and depends on other(s) for his/her care. Lower continuity of care has been associated with higher rates of adverse outcomes for persons with multiple chronic medical conditions [3].

Proper care transition and good management could decrease own care costs by reducing the number of consultations in revenues and hospital readmissions, complications of care, and improve the quality of life of elderly dependent on care and their families [4]. Economic pressures and care complexities of the aged require improved effectiveness and efficiencies in the information transfer process. For addressing these complex chronic patients and their caregivers, arise in different countries and at different times, models of care known as "Case Management Models", whose main support is nursing. The role of Nurse Case Manager is well developed, with the aim of providing quality results and cost effective in the care of these patients [5]. Using a model of advanced practice nursing as Case Management allows all health workers involved in the therapeutic coordinate and plan social and health resources available in the comprehensive patient care are mobilized efficiently [6].

The development of these new profiles of nurses has been used for years in some countries like the US, Canada and the UK as a strategy to meet the needs of care and improve health services. Currently, initiatives for its development have spread globally, so that in countries like Brazil, Korea, South Africa, New Zealand or the Netherlands, has started the process of defining specific proposals for training and development legislation profiles of Nurse Practitioners [7]. In this study it is revealed that one of the main reasons for the development of new nursing roles is to improve access to health care in countries characterized by limited availability of medical contexts, but so is the concern for increasing quality care, by creating, for example, new profiles that allow nurses closer to a particular type of patients that require follow-up.

The development of new nursing roles is also considered a way to contain the cost of health services, since by delegating tasks to nurses, doctors have traditionally done, can maintain or increase services at lower cost [8]. 
Improving quality of care may also be a cost reduction in the long term, due to the prevention of complications of the disease and decrease unnecessary hospitalizations. It will also have a decisive impact on the quality of life of the elderly and their families [9].

Nurses need to reflect on the importance of careful management and exercise more decisively his caring role, ie, direct care, and reinforce their educational and research skills significantly transcend care practice [10].

Care transition can be strengthened from the hospital setting but also from the field of community nursing; to achieve knowledge, planning, implementation, monitoring and evaluation to ensure that care will continue at home is required, but also involves scientific and technical quality, warmth in the deal, assertive communication a teaching-learning intentional process bidirectionally between people ill and their caregivers [11].

It is improving a lot in this regard, but nurses still have yet to assume more leadership in care management and coordination between levels, especially elderly patient care, chronic, multimorbidity and therefore fragile [12].

\section{References}

1. Bloom DE, Canning D, Lubet A (2015) Global population aging: Facts, challenges, solutions \& perspectives. Daedalus 144: 80-92.

2. International Council of Nurses (2006) The roles of nursing in health care services. Nursing care for the elderly. Geneva.

3. Bayliss EA, Ellis JL, Shoup JA, Zeng C, McQuillan DB, et al. (2015) Effect of continuity of care on hospital utilization for seniors with multiple medical conditions in an integrated health care system. Ann Fam Med 13: 123-129.

4. Thraen I, Bair B, Mullin S, Weir CR (2012) Characterizing "information transfer" by using a Joint Cognitive Systems model to improve continuity of care in the aged. Int $\mathrm{J}$ Med Inform 81: 435-441.

5. Kirsebom M, Wadensten B, Hedström M (2013) Communication and coordination during transition of older persons between nursing homes and hospital still in need of improvement. J Adv Nurs 69: 886-895.

6. Gjevjon ER, Romøren TI, Kjøs BØ, Hellesø R (2013) Continuity of care in home health-care practice: Two management paradoxes. J Nurs Manag 21: 182-190.

7. Sheer B, Wong FK (2008) The development of advanced nursing practice globally. J Nurs Scholarsh 40: 204-211.

8. Delamaire M, Lafortune G (2010) Nurses in advanced roles: A description and evaluation of experiences in 12 developed countries. OECD Health Working Papers, No. 54, OECD Publishing, Paris.

9. Bentler SE, Morgan RO, Virnig BA, Wolinsky FD (2014) Evaluation of a patient-reported continuity of care model for older adults. Qual Life Res 23: 185-193.

10. Pulcini J, Jelic M, Gul R, Loke AY (2010) An international survey on advanced practice nursing education, practice, and regulation. J Nurs Scholarsh 42: 31-39.

11. Meleis Al, Sawyer LM, Im EO, Hilfinger Messias DK, Shumacher K (2000) Experiencing transitions: An emerging middle range theory. Adv Nurs Sci 23: 12-28.

12. Veras RP, Caldas CP, Motta LBD, Lima KC, Siqueira RC, et al. (2014) Integration and continuity of Care in health care network models for frail older adults. Rev Saude Publica 48: 357-365. 